\title{
Using a Thermal Proxy to Examine Sediment-Water Exchange in Mid-Continental Shelf Sandy Sediments
}

\author{
William B. Savidge ${ }^{1}$ (D) Alicia Wilson ${ }^{2,3} \cdot$ Gwendolyn Woodward $^{3}$
}

Received: 23 September 2015/Accepted: 17 May 2016/Published online: 30 May 2016

(C) The Author(s) 2016. This article is published with open access at Springerlink.com

\begin{abstract}
Fluid exchange across the sediment-water interface in a sandy open continental shelf setting was studied using heat as a tracer. Summertime tidal oscillation of cross-shelf thermal fronts on the South Atlantic Bight provided a sufficient signal at the sedimentwater interface to trace the advective and conductive transport of heat into and out of the seabed, indicating rapid flushing of ocean water through the upper $10-40 \mathrm{~cm}$ of the sandy seafloor. A newly developed transport model was applied to the in situ temperature data set to estimate the extent to which heat was transported by advection rather than conduction. Heat transported by shallow 3-D porewater flow processes was accounted for in the model by using a dispersion term, the depth and intensity of which reflected the depth and intensity of shallow flushing. Similar to the results of past studies in shallower and more energetic nearshore settings, transport of heat was greater when higher near-bed velocities and shear stresses occurred over a rippled bed. However, boundary layer processes by themselves were insufficient to promote non-conductive heat transport. Advective heat transport only occurred when both larger boundary layer stresses and thermal instabilities within the porespace were present. The latter process is dependent on shelf-scale heating and cooling of bottom water associated with upwelling events that are not coupled to localscale boundary layer processes.
\end{abstract}

Keywords Continental shelf $\cdot$ Permeable sediments $\cdot$ Sediment-water exchange $\cdot$ Inverse model

William B. Savidge

william.savidge@skio.uga.edu

1 Skidaway Institute of Oceanography, University of Georgia, 10 Ocean Science Circle, Savannah, GA 31411 , USA

2 Department of Earth and Ocean Sciences, University of South Carolina, 701 Sumter Street EWS 617, Columbia, SC 29208, USA

3 Environment and Sustainability Program, University of South Carolina, Columbia, SC 29208, USA 


\section{Introduction}

Numerous recent lines of evidence have demonstrated that permeable sandy coastal sediments can support high diagenetic reaction rates despite very low standing stocks of sedimentary carbon (De Beer et al. 2005; Huettel and Rusch 2000; Rao et al. 2007; Jahnke et al. 2005). Rapid metabolism within permeable sediments is promoted by regular exchanges of pore water with bottom water, which allows for replenishment of oxidants and reactive fine particulate and dissolved matter within the pore space (Huettel and Rusch 2000; Ehrenhauss and Huettel 2004; Gihring et al. 2010). The enhancement of benthic metabolism within advectively influenced permeable sediments has been shown to be proportional to the rate of water flux through the pore space (Reimers et al. 2004; Janssen et al. 2005; Rusch et al. 2006; Cook et al. 2007; Berg et al. 2013). Close coupling of physical forcing and biological responses is mediated by diverse assemblages of microbes within pore space that can react quickly to changes in oxidant or organic matter availability (Franke et al. 2006; Hunter et al. 2006; Mills et al. 2008; Gihring et al. 2009). In a recent review, Heuttel et al. (2014) estimated that remineralization within permeable sandy sediments on continental shelves may account for 4-13\% of total respiration on continental shelves, and $15 \%$ of global sedimentary denitrification. However, because of the technical difficulties of working in sandy permeable sediments, the observational basis for these numbers remains limited, and the actual contribution of permeable sediment processes to global continental shelf metabolism is still poorly constrained. Refinement of these estimates will require accounting of forcing and response over a broader spectrum of environments and over longer periods of time.

Advective circulation of seawater through seafloor sediments may be forced by several mechanisms, including wave pumping, density instabilities, and interactions between currents and seafloor topography. In shallow water with strong wave energy, bottom water can penetrate 10-20 cm below the seabed (Hebert et al. 2007; Fogaren et al. 2013; Fram et al. 2014).

During wave pumping, pressure gradients at the sediment-water interface created by the passage of wave crests and troughs induce vertical and horizontal movement of water within the seabed (Riedl et al. 1972; Harrison et al. 1983; Webster 2003). The effectiveness of wave-driven transport is commonly thought to decline rapidly with increasing water depth. However, Webster's (2003) theoretical treatment of wave pumping is based on shear dispersion within intergranular pores rather than rotational dispersion and predicts that wave-induced porewater mixing can be effective in deeper waters on the open shelf. He estimated that the wave field on the continental shelf of the South Atlantic Bight at a water depth of $27 \mathrm{~m}$ could increase the diffusion of solutes by $\sim 40 \times$ relative to molecular diffusion.

Density instabilities develop when cold floodwaters overtop warmer porewaters, for example when cold waters overtop intertidal flats (Webster et al. 1996; Rocha 2000) or intrude over warmer sediments due to seiches (Moore and Wilson 2005; Kirillin et al. 2009). Density instabilities also develop when porewaters are diluted by submarine freshwater discharge (Smith 2004; Santos et al. 2012b; Konikow et al. 2013). In these cases, convective overturn of porewater can lead to rapid exchange of porewater and bottom water. In addition, flume experiments (Boano et al. 2009; Jin et al. 2011) have shown that small destabilizing density gradients have the capacity to significantly increase the rate and depth of exchange in systems where surficial pressure gradients provide the primary impetus to porewater exchange. 
Advective exchange across the sediment-water interface is also driven by hydraulic gradients caused by the interaction of currents and seafloor topography. The advective flow that occurs in response to these interactions may be a major driver of physically forced benthic exchange over most continental shelves, especially at greater depths where surface wave energy is attenuated. Experimental (Huettel et al. 1998; Huettel and Gust 1992; Precht and Huettel 2004) and modeling studies (Meysman et al. 2007; Cardenas and Wilson 2007a, b; Cardenas et al. 2008) have demonstrated that the interaction of boundary flows with topographic features on the seafloor create a predictable patchwork of pressure variation at the interface. Bottom water enters the porespace at the interface at regions of high pressure and exits at locations of lower pressure. Numerical models have further refined our understanding material transport and transformation within permeable sediments (Cardenas et al. 2008; Kessler et al. 2012, 2013). Field experiments have demonstrated that volumetric circulation within porespace can be significant (Webb and Theodor 1972; Reimers et al. 2004; Precht and Huettel 2004; Hebert et al. 2007; Fram et al. 2014) and support the contention that advective circulation through porespace is a major determinant of shelf-scale biogeochemical processes (Rao et al. 2007; Santos et al. 2012a; Heuttel et al. 2014).

Direct field measurements of porewater fluxes have been obtained by injecting dye into or above sediments to trace the movement of fluid into or out of the seabed (Reimers et al. 2004; Precht and Huettel 2004; Hebert et al. 2007). While the method has provided good insights into the rate of advective velocities in pore water, direct measurement of water flow within porewater is cumbersome and imprecise. As an alternative, heat flux has been used extensively as a proxy for fluid flux in limnology and groundwater studies (Anderson 1995; Constantz 2008). In general terms, these models build on original models of Suzuki (1960) and Stallman (1965) to predict the unidirectional advective flux of fluid through the beds by examining the propagation of a steady-state sinusoidal temperature signal to depth (e.g., Silliman et al. 1995; Hatch et al. 2006; Keery et al. 2007; Vogt et al. 2010; Rau et al. 2010). Heat is assumed to be transported by conduction and one-dimensional steady flow of groundwater. Attenuation and phase shifts of the signal imposed at the boundary are indicative of steady advective transport. Some models attempt to deal with transient forcing (Vogt et al. 2010; Schmidt et al. 2014), but none capture the complex dynamics of variable, wave- and tidally driven benthic exchange that are characteristic of permeable marine sediments.

Firmer constraints upon the global importance of advectively driven geochemistry in permeable sediments will require more extensive understanding of the range of potential driving forces for fluid exchange and the spatial and temporal variability in the response below the seafloor. Temporal variability has the potential to be particularly important. Autumn storms can greatly alter sediment topography by creating long-wavelength highamplitude ripple fields (Komar et al. 1972; Voulgaris unpublished) that could greatly increase the scale and intensity of sediment-water exchange. On finer temporal scales, porewater flows have been shown to vary significantly on time scales on the orders of minutes (Reimers et al. 2004) or less (Cardenas and Jiang 2011). In contrast, modeling (Kessler et al. 2012) and experimental (e.g., Cook et al. 2007, Rao et al. 2007; Gihring et al. 2010; Gao et al. 2010; Chipman et al. 2012) studies of porewater geochemistry under advective conditions have been evaluated under relatively steady flow conditions. While a great improvement over static incubations (e.g., Vance-Harris and Ingall 2005), the imposition of steady-state flows and geochemical gradients within porewaters may also underestimate the rate of mineralization within a dynamic geochemical environment. To date, this variability is not accommodated within global or regional assessments of 
sedimentary biogeochemical transformations. Inclusion of these processes in assessments of the contribution of porewater advection to sediment geochemistry will require more continuous high resolution measurement of porewater exchange fluxes.

In this manuscript, we describe an effort to measure porewater exchange at high resolution using heat as a tracer on an open shelf environment where prior studies (Marinelli et al. 1998; Jahnke et al. 2005) have indicated that advective pore water exchange is present. To estimate exchange rates from heat flux, we developed a novel modeling approach (Wilson et al. 2016) that consists of a forward optimization routine to find a best fit of the advection-dispersion equation to observed profiles. The method allows for high temporal resolution of porewater flushing in response to temporally variable forcing. The model treats heat transfer by bottom water-porewater exchange as an enhanced dispersive process rather than as a strictly advective process, which allows complex 3-D flows to be approximated in an efficient 1-D framework. The enhanced dispersion formulation has been useful for characterizing porewater solute properties and reaction rates in seafloor (Berg et al. 1998) and hyporheic (Bhaskar et al. 2012) settings. The model explicitly assumes only that the strength of the external forcing declines exponentially with depth (e.g., Shum 1992; Jahnke et al. 2005; Fram et al. 2014). As described below, application of the model to a sediment temperature time series indicates that the intensity and timing of mixing events on the mid-shelf of Georgia USA are related to both local tidal boundary layer processes and thermal gradients across the interface generated by shelf-scale upwelling and downwelling episodes.

\section{Methods}

\subsection{Study Site}

Two successful thermistor probe deployments were made on the mid-shelf of Georgia, USA $\left(3122^{\prime} \mathrm{N}, 8034^{\prime} \mathrm{W}\right)$, approximately $50 \mathrm{~km}$ east of St. Catherine's Island. Mean water

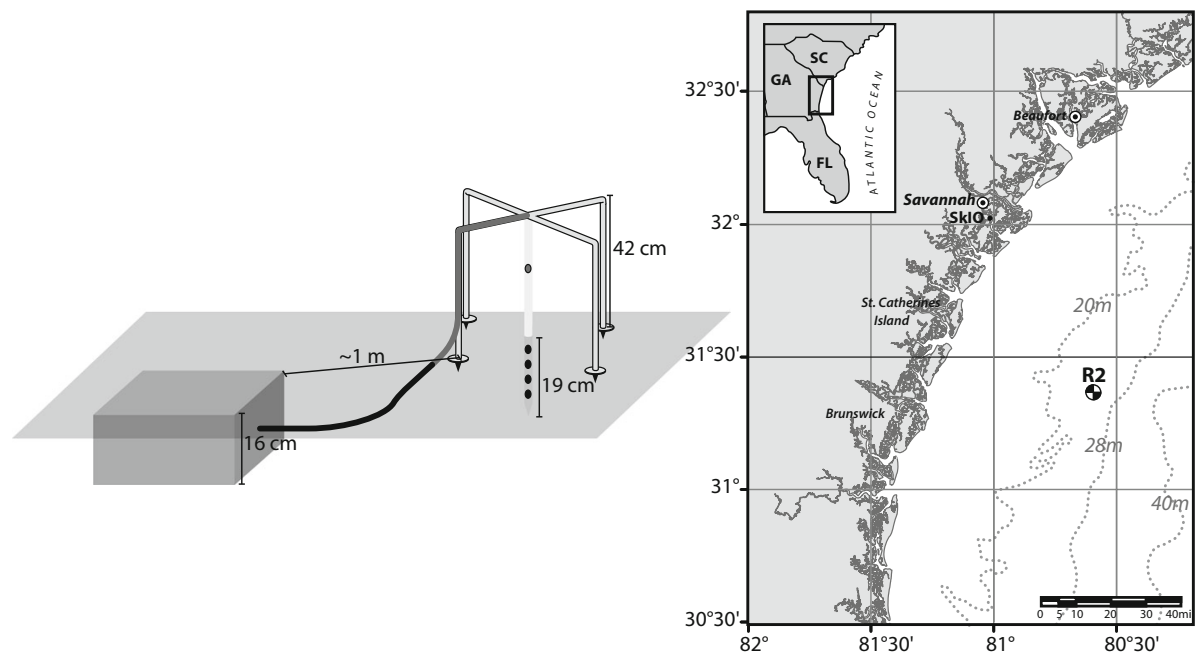

Fig. 1 Design and location of the thermistor deployment on the GA continental shelf at R2 
depth was $27 \mathrm{~m}$ (Fig. 1). The site was the location of the SABSOON and BOTTOMS-UP ocean observatories (http://skio.uga.edu/?p=research/phy/bottomsup/bottomsup). Tide, wave, current, and bottom water temperature data were obtained from observatory instrumentation. In this region of the mid-shelf, the cross-shelf tidal excursion is $\sim 13-14 \mathrm{~km}$ and tidal range is $\sim 2 \mathrm{~m}$ (Blanton et al. 2004). Water movement at the sediment-water interface is dominated by tidal currents (maximum velocity $=45 \mathrm{~cm} \mathrm{~s}^{-1}$ ) during the summer months when low wind and wave conditions prevail. Sediments at the site are highly permeable medium sands $\left(\kappa=4.7 \times 10^{-11} \mathrm{~m}^{2}\right.$ : Rao et al. 2007). Concentrations of fines $(<63 \mathrm{um})$ in surface sediments are $<0.3 \%$ by weight (Savidge, unpublished data). The benthic fauna consists of a sparse assemblage of small polychaetes and amphipods (Marinelli et al. 1998, Savidge, unpublished data) that is unlikely to contribute materially to particle or porewater mixing. Organic matter deposition and nutrient recycling are driven by advective fluxes of bottom water through the permeable sand bed (Jahnke et al. 2005; Rao et al. 2007).

\subsection{Probe Design}

In situ temperature data were acquired by a string of BetaTHERM 100K6A11A thermistors. Individual thermistors were soldered to $0.15 \mathrm{~mm}$ diameter Ag-coated copper wires and embedded in holes drilled into a CPVC tube (thermal conductivity $=0.137 \mathrm{~W} \mathrm{~m}^{-1} \mathrm{~K}^{-1}$ ). Thermistors were fixed in place with a thermally conductive epoxy (MG Chemicals 8331-14G). The tube was split longitudinally during construction and was re-glued and potted with a non-conductive epoxy to seal the wiring and add strength to the shaft. The distal end of the shaft was terminated with a stainless steel cone point to facilitate probe penetration into the well-packed sands. Overall shaft dimensions were $61.5 \mathrm{~cm}$ length $\times 1.25 \mathrm{~cm}$ dia. thermistors were located at $+10,-3,-6,-9$, and $-12 \mathrm{~cm}$ from the sediment-water interface when the probe was inserted. At the other end of the shaft, the thermistor wires were passed through a cable sheath with a water-tight 10-pin termination. On the seafloor, the cable and probe were supported above the interface by a four-legged frame constructed from the $0.5-\mathrm{cm}$-diameter stainless steel rod. The cable termination was connected to a $16 \times 24 \times 30.5 \mathrm{~cm}$ pressure case. Inside the case was mounted a Campbell Scientific CR1000 Measurement and Control Module and a 6-V motorcycle battery as a power source. A second, 8-pin penetrator in the case allowed for data transfer and battery recharging.

\subsubsection{Probe Calibration}

The thermistors had a rated accuracy of $\pm 0.1 \mathrm{C}$ (BetaTHERM). Shipboard calibrations of the thermistors were attempted, but the calibration system failed to achieve constant temperatures within the long water column. However, a failed deployment in May-June 2008 provided a serendipitous long-term calibration prior to the June-July deployment. During that deployment, the probe assembly was overturned (probably by a large shark or ray) and the entire probe was exposed in the bottom boundary layer. This long soak revealed only small temperature offsets among the thermistors, and no relative thermistor drift. Unfortunately, the damage to the probe in situ (see Sect. 3) prevented an analogous post-deployment calibration in August 2008. 


\subsection{Probe Deployment}

Successful probe deployments were conducted between June 20 and July 9 (JJ deployment), and July 11 and July 30 (JA deployment), 2008. Before each deployment, the Campbell CR1000 was programed to sample each thermistor at 1-min intervals. The probe apparatus was hand-carried to the sea floor by divers. The divers pushed the probe vertically into the sand until the upper thermistor was $10 \mathrm{~cm}$ above the local interface. The pressure case was then buried in the sand about $0.75 \mathrm{~m}$ from the probe in order to minimize the surface flow and topographic artifacts. Because local sediment topography appeared flat to the divers, no specific locations were identified for deployment. The JJ and JA deployments were within a few meters of one another. In the deployment design, the probe was placed within the circle of view of an Imaginex imaging sonar so that the position of the shaft relative to local topography could be monitored (Fig. 2). Unfortunately, the sonar failed prior to the $\mathrm{JJ}$ deployment and was only operational between $7 / 29$ and 8/23 during the JA deployment. Images of the interface obtained during the 2008 summer season but before the JJ deployment show evidence of long-wavelength low-amplitude ripples prior to $6 / 12 / 2008$ (Fig. 2). Wavelengths of the ripples were $\sim 0.75 \mathrm{~m}$ at that time. Images from $7 / 29-8 / 03$ show a more eroded and rumpled benthic topography and a somewhat different orientation of the ripple field in late July than in early June. Sonar shadows from the probe shaft and battery case are clearly visible in the image. Unfortunately, the shaft was placed in a region of the field of view in which sonar resolution of benthic topography was poor, and its position relative to local topography is ambiguous.

\subsection{Data Analysis}

Raw thermistor data were first corrected for temperature offsets among individual thermistors obtained from the May-June deployment attempt. The raw data were then subject to a 120 -min running average to eliminate the random digital noise in the signal. Shorter averaging intervals retained physically unrealistic "stair-stepped" temperature gradients. Only data records $i=516$ to 12,512 (JJ) and $i=510$ to 28,735 (JA) were used in the subsequent analyses. Data prior to those times were potentially compromised by deployment artifacts. Data from the JJ deployment after June 29th were rejected because of thermal evidence for possible probe disturbance (see Sect. 4). Inspection of the JA data indicated that temperatures at the $+10 \mathrm{~cm}$ sensor began to drift relative to a nearby

(a) June 2008

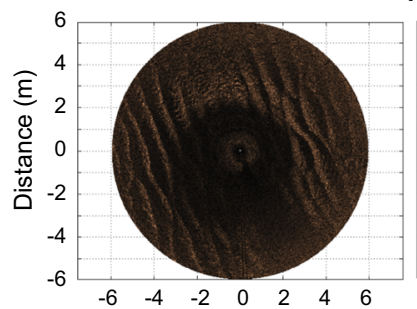

(b) July 2008

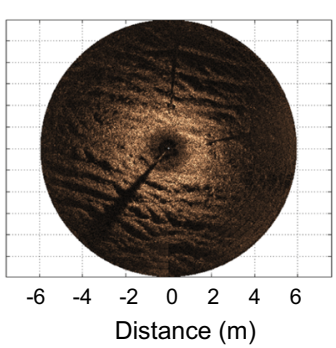

(c) August 2008

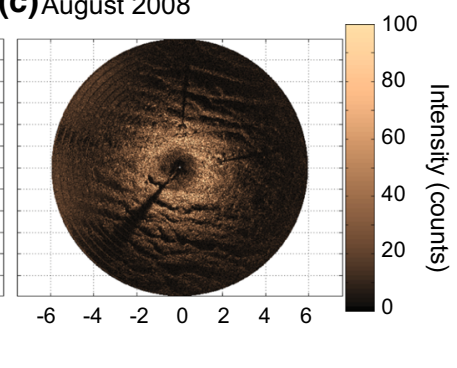

Fig. 2 Imaginex sonar imagery showing bottom topography prior to the JJ deployment (left) and at the end and shortly after the JA deployment (center and right). Thermistor assembly and battery box are visible in the latter images 
$(<0.5 \mathrm{~km})$ ADCP temperature sensor beginning on July 14th. A linear drift correction was applied to the $+10 \mathrm{~cm}$ thermistor, but after July 30th the signal became further degraded and the data record was truncated at that point. Post-deployment inspection of the probe indicated that the probe shaft had developed fine cracks that allowed salt water to infiltrate the structure and short the wiring.

\subsection{Modeling of Porewater Temperatures}

As discussed more fully by Wilson et al. (2016), transport of heat via shallow 3-D hydrodynamic flushing can accommodated in a 1-D framework via the addition of an effective dispersion term

$$
\left(\phi \rho_{f} c_{f}+(1-\phi) \rho_{\mathrm{s}} c_{\mathrm{s}}\right) \frac{\partial \mathrm{T}}{\partial \mathrm{t}}=\left(\lambda^{*}+D_{\mathrm{eff}}\right) \frac{\partial^{2} \mathrm{~T}}{\partial \mathrm{z}^{2}}-\phi \rho_{f} c_{f} v \frac{\partial \mathrm{T}}{\partial}
$$

where $\phi$ is the porosity of the sediment, $\rho_{f}$ is the density of water, $c_{f}$ is the specific heat capacity of water, $\rho_{\mathrm{s}}$ is the density of the solid grains, $c_{\mathrm{s}}$ is the specific heat capacity of the solid grains, $\lambda^{*}$ is the effective thermal conductivity of the saturated sediment, $v$ is the average linear velocity of the groundwater, $z$ is the depth below the sediment-water interface (positive downward) and $D_{\text {eff }}$ is the effective dispersion coefficient (Table 1 ). The effective dispersion coefficient decays exponentially with depth below the sediment-water interface (Elliott and Brooks 1997; Jahnke et al. 2005; Qian et al. 2008, 2009), so that

$$
D_{\text {eff }}=D_{o} e^{-k z}
$$

where $k$ is

$$
k=\frac{\ln (2)}{d_{1 / 2}}
$$

and $d_{1 / 2}$ is the half-depth, which is the depth below the sediment-water interface at which $D_{\text {eff }}=D_{\mathrm{o}} / 2$. The exponential model also makes the implicit assumption that the

Table 1 Parameters for the heat transport model

\begin{tabular}{llll}
\hline Parameter & Definition & Value & Units \\
\hline$\phi$ & Porosity & 0.40 & {$[-]$} \\
$\rho_{f}$ & Density of seawater & 1025 & $\mathrm{~kg} \mathrm{~m}^{-3}$ \\
$\rho_{\mathrm{s}}$ & Density of sediment grains & 2650 & $\mathrm{~kg} \mathrm{~m}^{-3}$ \\
$c_{f}$ & Specific heat capacity of seawater & 3993 & $\mathrm{~J} \mathrm{~kg}^{-1} \mathrm{~K}^{-1}$ \\
$c_{\mathrm{s}}$ & Specific heat capacity of sediment grains & 1170 & $\mathrm{~J} \mathrm{~kg}^{-1} \mathrm{~K}^{-1}$ \\
$\lambda^{*}$ & Effective thermal conductivity & 2.00 & $\mathrm{~W} \mathrm{~m}^{-1} \mathrm{~K}^{-1}$ \\
$v$ & Vertical groundwater flow rate & $1.5^{\mathrm{a}}$ & $\mathrm{m} \mathrm{gr}^{-1}$ \\
$D_{\text {eff }}$ & Effective dispersion coefficient & & $\mathrm{W} \mathrm{m}^{-1} \mathrm{~K}^{-1}$ \\
$D_{\text {int }}$ & Total integrated dispersion & & $\mathrm{W} \mathrm{K}{ }^{-1}$ \\
TDI & Thermal diffusivity index & & {$[-]$} \\
\hline
\end{tabular}

${ }^{\text {a }}$ In the upward direction 


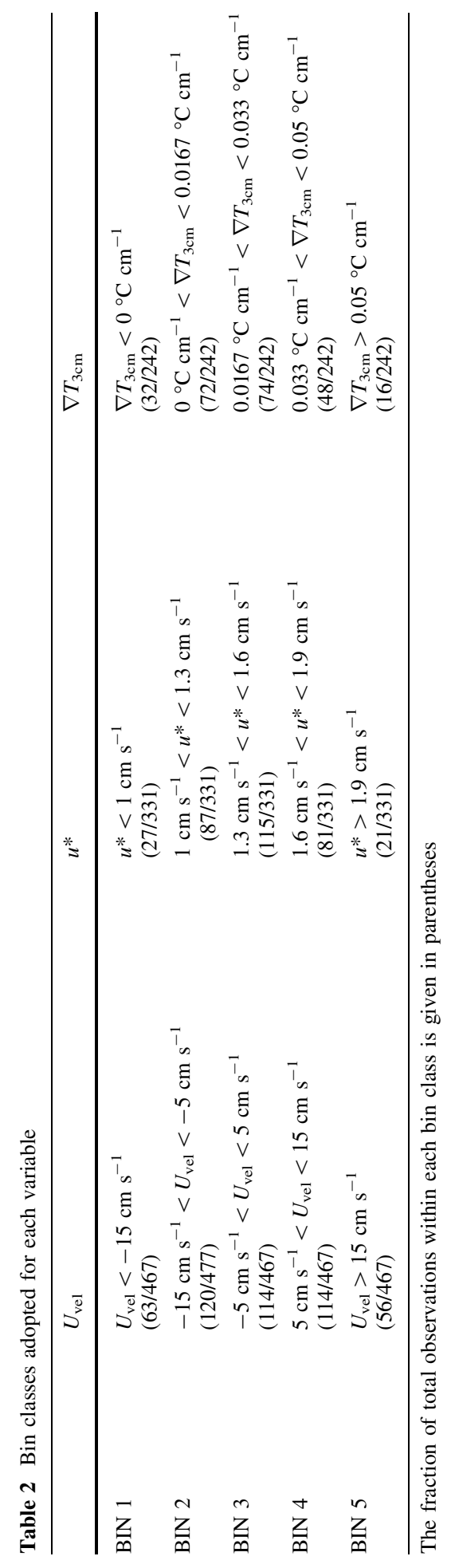


permeability of the sediment is constant over the depth range being evaluated. Both $D o$ and $k$ are allowed to vary in time.

The model described by Wilson et al. (2016) inverts thermal data to determine the minimum $D_{\text {eff }}$ required to match the field observations. The program reports the thermal diffusivity index (TDI), where

$$
\mathrm{TDI}=D_{\mathrm{eff}} / \lambda^{*}
$$

The TDI therefore indicates whether heat transport is dominated by effective dispersion (TDI > 3) or by heat conduction (TDI < 0.3) (Bhaskar et al. 2012). The total integrated addition of dispersion is expressed as:

$$
D_{\text {int }}=\int_{0}^{\infty} D_{\text {eff }} \mathrm{d} z=\int_{0}^{\infty} D_{o} e^{-k z} \mathrm{~d} z=\frac{D_{o}}{k}=\frac{D_{o} d_{1 / 2}}{\ln (2)}
$$

The model solves the heat transport Eq. (1) using a 1-D triangular finite element method. The temperature of the upper (seafloor) boundary was specified based on field observations of the bottom water temperature. The simulation domain extended downward $10 \mathrm{~m}$ below the seafloor, at which depth the temperature was specified to be the average annual temperature. TDI and $D_{\text {int }}$ were calculated over sequential 15-min time intervals. Details of model performance and sensitivity using both field and synthetic data are provided in Wilson et al. (2016)

Spectral and correlation analyses were conducted in Matlab using the Time Series and Signal Processing Toolboxes ${ }^{\circledR}$. Standard time series methods were not appropriate because the calculated exchange was non-stationary. Environmental variables were tidally cyclic. We examined a large suite of variables that were collected at the site as part of the BOTTOMS-UP observatory program, including internal and surface waves, water column stratification, and turbulence. As described in more detail below, we found that only crossshelf tidal velocity $\left(U_{\text {vel }}\right)$ and shear velocity $\left(u^{*}\right)$ proved useful. We also examined the thermal gradient from the upper $3 \mathrm{~cm}$ of the sediment $\left(\nabla T_{3 \mathrm{~cm}}\right)$, because advection during significant flushing episodes causes sub-seafloor temperatures to converge to the bottom water temperature. It is not possible to identify flushing events solely by looking for times when $\nabla T_{3 \mathrm{~cm}}=0$, because this can occur in response to heat conduction alone, and it is difficult to decide how deep flushing reaches using simple analyses of $\nabla T$. However, $\nabla T_{3 \mathrm{~cm}}$ provides a useful check of the model, because instances of flushing identified by the model should coincide with instances of low $\nabla T_{3 \mathrm{~cm}}$.

In order to identify associations between instances of large values of $D_{\text {int }}$ and particular environmental variables, each independent variable was first divided into five approximately equivalent bin classes (Table 2). Each bin entry consisted of the average of all consecutive occurrences of that variable within that bin class. For example, as the tidal moves from full ebb $\left(U_{\mathrm{vel}} \sim 0\right)$ to full flood $\left(U_{\mathrm{vel}} \sim 0\right)$, there will be a portion of that time when $U_{\text {vel }}<15 \mathrm{~cm} \mathrm{~s}^{-1}$. All time points when $U_{\text {vel }}$ was $<15 \mathrm{~cm} \mathrm{~s}^{-1}$ were averaged, and that average became a single entry in the $U_{\text {vel }}<15 \mathrm{~cm} \mathrm{~s}^{-1}$ bin for the entire time series. We then calculated the average of all $D_{\text {int }}$ entries within the same bin. This treatment served to make each (averaged) bin value independent by removing the autocorrelation between values that would be present if each sequential observation was treated a unique sample. We tested for differences in median $D_{\text {int }}$ among bin classes using a Kruskal-Wallis test. In addition, we tested whether larger values of $D_{\text {int }}$ were non-randomly distributed among bins using a Chi-square test for goodness of fit. 
Following prior studies (Fram et al. 2014), we also examined the time lag in the propagation of the tidal temperature signal to depth. Time lags were calculated using the Matlab xcorr routine, using the 1-min smoothed data and a sliding $1490 \mathrm{~min}$ ( 2 tidal cycle) window.

\section{Results}

Two modes of temperature variation are apparent in the porewater time series collected between $6 / 20 / 08$ and $7 / 29 / 08$. Long period ( $>1$ week), large amplitude $\left(2-3{ }^{\circ} \mathrm{C}\right)$ temperature fluctuations are overlain by smaller $\left(\leq 0.5^{\circ} \mathrm{C}\right)$ fluctuations on a tidal period (Fig. 3). The former are caused by variation in the strength of wind-driven upwelling of cool deep
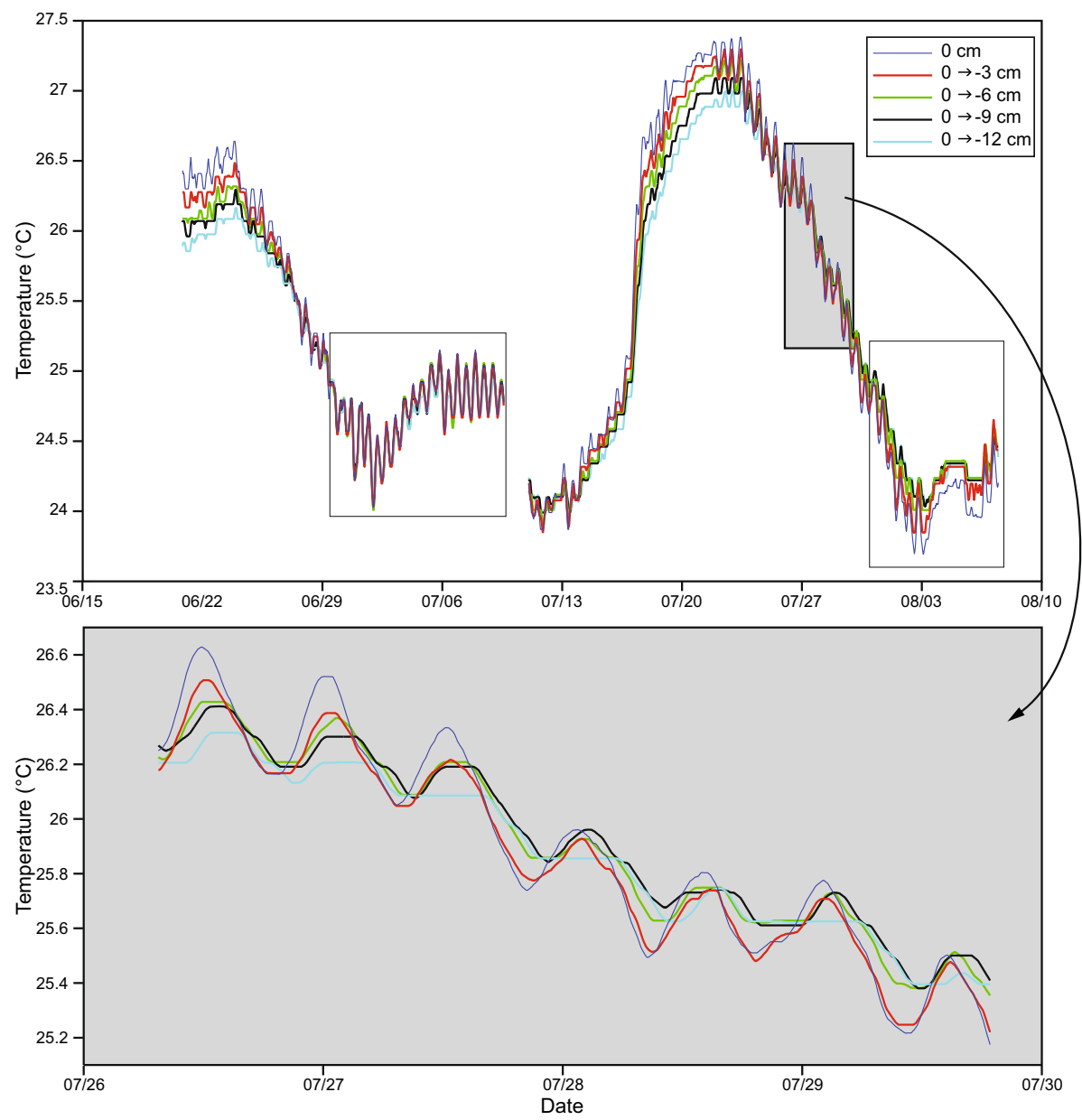

Fig. 3 Temperature records for the two deployments from summer 2008. Data within the boxes were not included in the analyses. See (Sect. 2) text for explanations. Detail of the temperature signal is shown in the shaded box 
water at the shelf edge and its displacement shoreward across the shelf (e.g., Lee et al. 1991). The smaller tidal fluctuations reflect the oscillation of the cross-shelf temperature gradient between the cooler offshore water and the warmer inshore water across the site. Two instances of prolonged cooling are seen in the record (6/24/08-7/01/08 and 7/23/08-8/ 03/08) interrupted by a rapid warming of bottom water and pore water between 7/13/08 and $7 / 23 / 08$, when cooler upwelled water was advected offshore and replaced by warmer shelf water. The first (JJ) deployment also appears to have begun during a time when the site was overlain by warm shelf waters. The tidal signal was readily apparent during the cooling phases of the record but was absent during the warming phase when the front was displaced sufficiently offshore that the tidal excursion did not transport cooler water over the site.

Temperature fluctuations at the interface were propagated rapidly to depth by both conduction and advection. Conductive heat transport was evident in the lag correlation analysis (Fig. 4). Heat transport showed a pattern of propagation of a semidiurnal temperature signal to shallow depths within the sediment transitioning to a diurnally dominated signal at greater depths. Correlation coefficients from the lag analyses were generally $>0.9$ for depths $\leq 9 \mathrm{~cm}$ and 0.8 for the $12 \mathrm{~cm}$ depth. The time lags between 0 and $3 \mathrm{~cm}$ ranged from 0 to $45 \mathrm{~min}$, for $0-6 \mathrm{~cm}$ it ranged from 0 to $78 \mathrm{~min}$, for $0-9 \mathrm{~cm}$ it ranged from 0 to $120 \mathrm{~min}$, and for $0-12 \mathrm{~cm}$ it ranged from 0 to $190 \mathrm{~min}$. Over all depth ranges, 0 lags relative to the interface was the most common state. Most of these instances in JA occurred between 7/13 and 7/21 when water temperatures were rising and temperatures, particularly at depth, did not display significant tidal oscillation. During these intervals, the absence of an imposed temperature signal at the interface invalidated the lag correlation analysis. There are no lags between parallel lines. Excluding instances in which lags were estimated at $0 \mathrm{~min}$, the median lags for each depth were 17, 41, 69 and $93 \mathrm{~min}$ for the $0-3,0-6,0-9$ and $0-12 \mathrm{~cm}$ intervals, respectively. These correspond to temperature propagation rates of $10.8,8.8,7.8$ and $7.7 \mathrm{~cm} \mathrm{~h}^{-1}$, respectively. No significant differences in temperature propagation rate between the $\mathrm{JJ}$ and JA deployments were seen, indicating very similar rates of thermal conduction during both deployments.

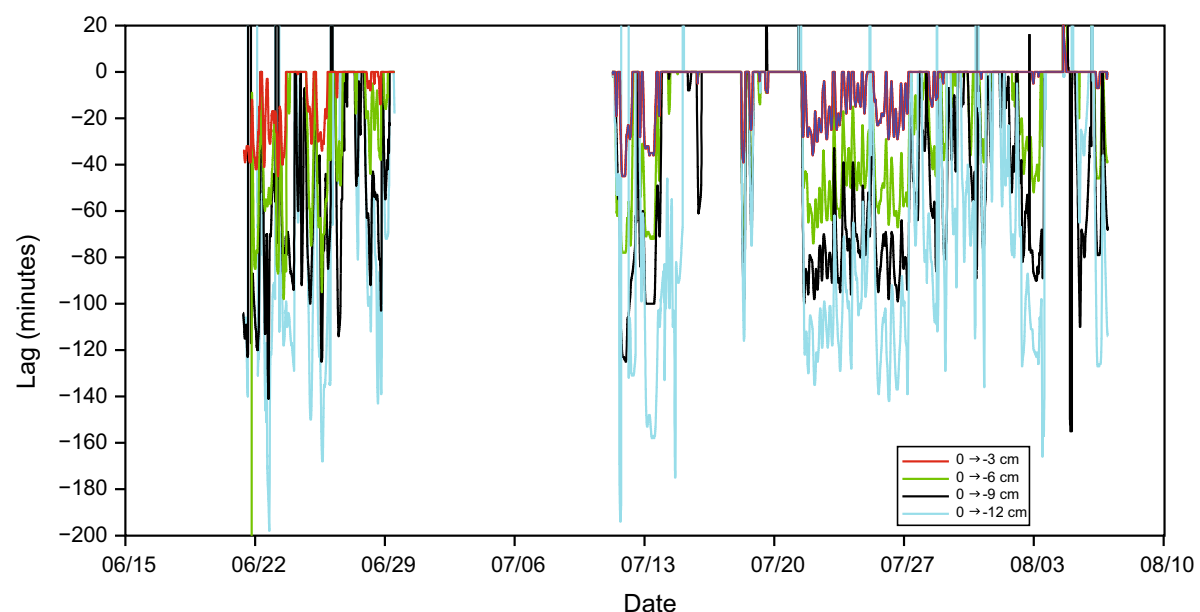

Fig. 4 Calculated time lags for the trimmed JJ and JA data sets. $Y$ axis is truncated. Large positive lags were associated with poor correlations between $D_{\text {int }}$ s at different depths 
Model calculations revealed significant periods where conduction explained the thermal signal as well as numerous instances when observed changes in temperature at depth required additional advective exchange (Fig. 5). Clusters of advective events were identified during the latter portion of the JJ deployment, and during the beginning and latter half of the JA deployment (Fig. 5). The $D_{\text {int }}$ signal was episodic during these intervals, but periodograms showed weak semidiurnal ( $\mathrm{JJ}$ and $\mathrm{JA}$ ) and quarterdiurnal periodicity (JJ). During the JJ deployment, the quarterdiurnal periodicity was associated with peak tidal speeds in both the ebb and flood tides. Semidiurnal periodicity was associated with onshore flow during flood tides. The median duration of individual mixing events during both JJ and JA was $1.25 \mathrm{~h}$.

The semidiurnal and quarterdiurnal periodicities identified in $D_{\text {int }}$ suggest a simple tidal control of mixing intensity, but we found that tidal forcing alone was not sufficient to explain the observed temporal patterns of flushing. In particular, while tidal and wave forcing remained roughly constant over the period of deployment (Fig. 5), there were extended periods when no mixing was detected. Other environmental factors must contribute to the transport of heat into the porewater. Shear velocity $\left(u^{*}\right)$ at the interface results from both wave orbitals and tidal currents, with tidal contributions being about twice the
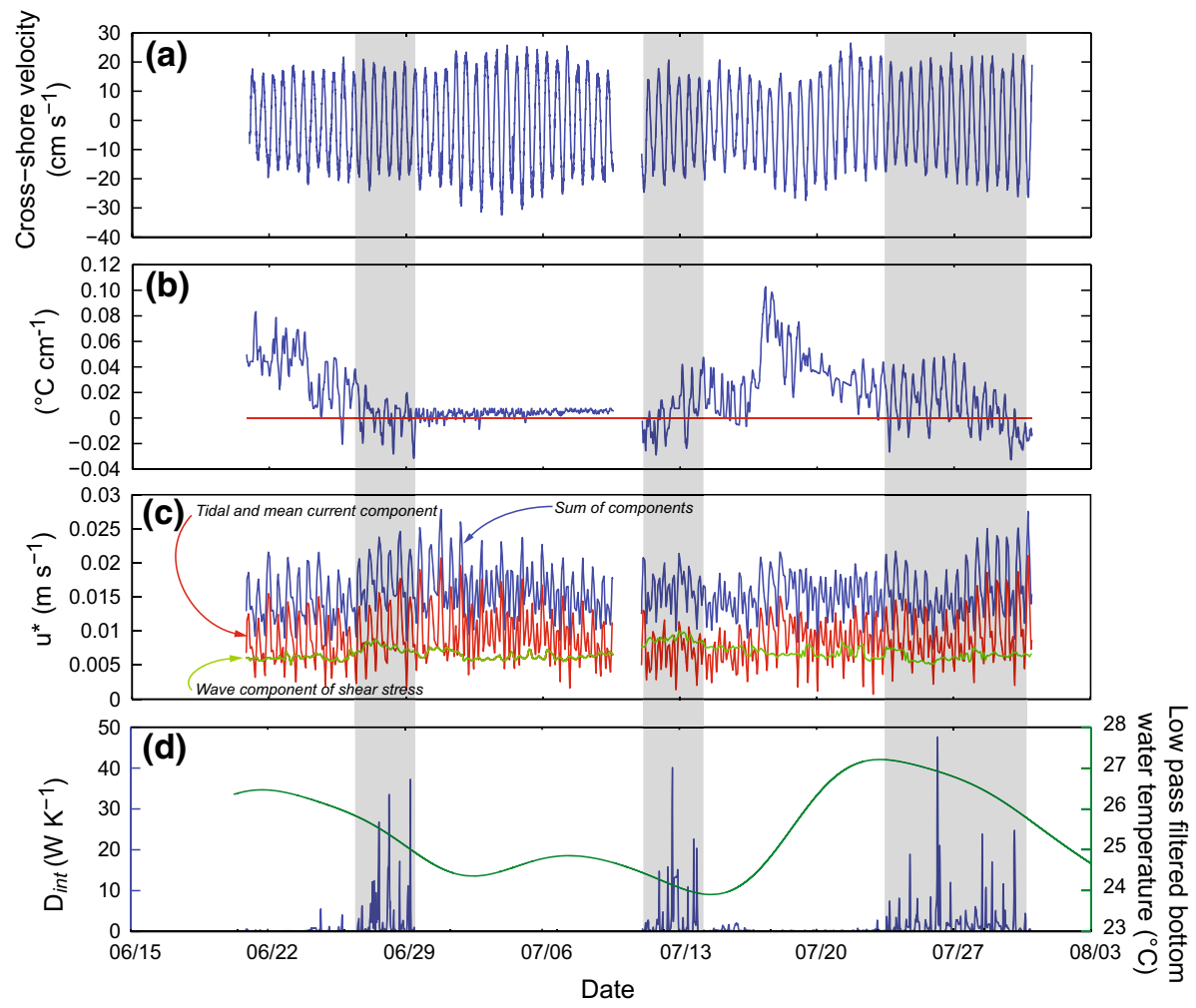

Fig. 5 Cross-shelf near bottom velocity (a), the temperature gradient between the upper two thermistors. The "flat lined" portion of the JJ record corresponds to the period of the deployment after the probe had been disturbed (see Sect. 2) (b), calculated wave, current and total shear velocity (c), and modeled $D_{\text {int }}$ and a $10^{5}$-min low-pass-filtered bottom water temperature signal (d) 
wave contribution during most of the deployment period (Fig. 5c). Two periods of enhanced bottom stress associated with passing atmospheric fronts, higher winds, and greater surface wave energy occurred during the field deployments. These events were associated with the transition between warming and cooling periods within the water column. The intervals of enhanced exchange during the JJ (June 26-29) and the latter portion of the JA record (July 24-August 3) coincided with periods of relatively high bottom stress. However, the period of enhanced exchange at the beginning of the JA measurement period (July 11-14) showed no such association. Wave-induced stresses were relatively high, but they were offset by low (neap) tidal stresses. In general, deep mixing events occurred only when minimum temperatures at the interface fell below temperatures at depth (Fig. 5b). The timing of the mixing during any particular event does not correspond to maximal negative temperature gradients (which occur at the peak flood tide when cross-shelf bottom water velocities are near zero), but to maximal mid-tidal onshore velocities (when vertical temperature gradients near the interface transition from positive to negative : Fig. 5b).

Consistent patterns between the strength of environmental forcing variables and the intensity of mixing could be discerned. Results for JJ and JA deployments were generally similar; results here are reported for pooled $(\mathrm{JJ}+\mathrm{JA})$ data. Overall, individual instances of large $D_{\text {int }}$ values were not associated exclusively with particular $U_{\text {vel }}, u^{*}$ or $\nabla T_{3 \mathrm{~cm}}$ bin classes. They could occur anywhere in the tidal cycle. However, when the data were binned and the median $D_{\text {int }}$ was calculated for each bin, higher median $D_{\text {int }}$ values were significantly associated with high flood tidal $U_{\mathrm{vel}}, u^{*}$ and $\nabla T_{3 \mathrm{~cm}}$ near the interface (Table 3).

These patterns can be further illustrated by comparing the proportion of large values of $D_{\text {int }}\left(D_{\text {int }}>1\right)$ within particular bin classes relative to the proportion of observations of $D_{\text {int }}<1$ within that bin class (Fig. 6). The observed distribution of large $D_{\text {int }}$ values relative to the expected (small $D_{\text {int }}$ ) distribution was different for all variables (Table 4 ). Large values of $D_{\text {int }}$ significantly underrepresented in low $U_{\text {vel }}$ bins, and they were overrepresented in high $U_{\text {vel }}$ bins. Only the $>15 \mathrm{~cm} \mathrm{~s}^{-1}$ bin results were statistically significant, suggesting that there is a directional bias, with more frequent occurrences of convective circulation during ebb tidal flows. Similarly, large values of $D_{\text {int }}$ occurred with greater frequency than low values of $D_{\text {int }}$ within the highest $u^{*}$ bin, and occurred with lower frequency in the lowest $u^{*}$ bin. The influence of the near-surface temperature gradient on the frequency of occurrence of large $D_{\text {int }}$ values was profound. Inverted or near-zero temperature gradients were associated with almost all instances of convective mixing. Larger positive gradients were never associated with mixing events (Fig. 6).

Periods of increased upwelling intensity and cooling bottom water were also associated with increasing intensification of the mid-water thermocline. We investigated the possibility that wave pumping or enhanced shear from internal waves could have contributed to

Table 3 Overall significance values obtained from Kruskal-Wallis comparisons for all values of $D_{\text {int }}$ within bins

\begin{tabular}{llr}
\hline$U_{\text {vel }}$ & BIN1 $>$ BIN3 & $P=0.002$ \\
$u^{*}$ & BIN5, BIN4, BIN3 $>$ BIN1 & $P<0.001$ \\
$\nabla T_{3 \mathrm{~cm}}$ & BIN1, BIN2 $>$ BIN3, BIN4, BIN 5 & $P<0.001$ \\
\hline
\end{tabular}

See Table 1 for bin values. Overall significance values are given. All reported post hoc multiple comparisons (Dunn's test) are significant at $P<0.05$ 

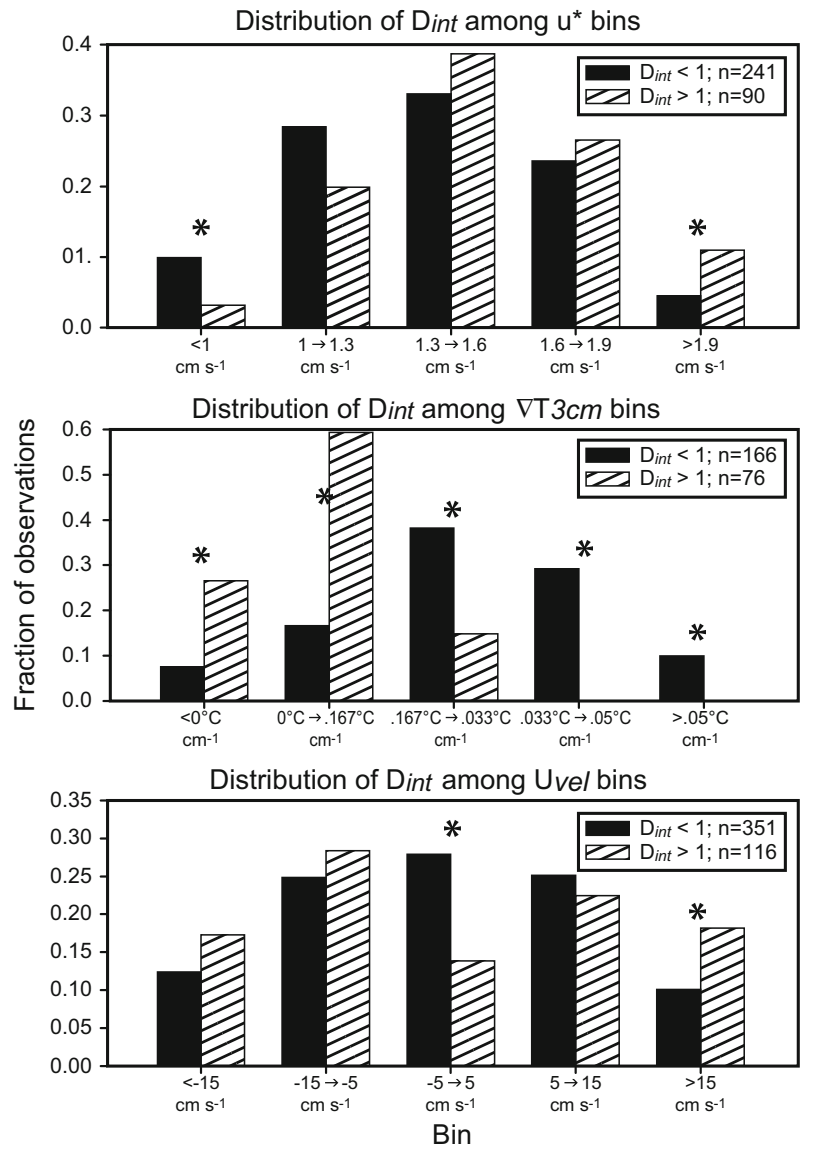

Fig. 6 Contrasts in the frequency of occurrence of $D_{\text {int }}>1$ among bin classes relative to the occurrence of observations of $D_{\text {int }}<1$ among bin classes. Asterisks denote significant differences on proportions. Total numbers of observations for each $D_{\text {int }}$ class are given in the legend

Table 4 Results of Chi-square goodness-of-fit tests contrasting the proportion of large values of $D_{\text {int }}$ within bin classes relative to the overall proportion of these bin classes

\begin{tabular}{llll}
\hline$D_{\text {int }}$ threshold & $U_{\text {vel }}$ & $u^{*}$ & $\nabla T_{3 \mathrm{~cm}}$ \\
\hline$D_{\text {int }}>1$ & $P=0.0003$ & $P=0.003$ & $P<0.00001$ \\
$D_{\text {int }}>2$ & $P=0.0003$ & $P=0.650$ & $P<0.00001$ \\
$D_{\text {int }}>4$ & $P=0.0010$ & $P=0.510$ & $P=0.00030$ \\
\hline
\end{tabular}

$P$ values indicate the probability that larger $D_{\text {int }}$ values have the same distribution among bins as small $D_{\text {int }}$ values for the three variables investigated

fluid exchange below the sediment-water interface. However, examination of the correspondence between vertical velocities measured by 5-beam ADCP in the water column (D. Savidge, unpublished data) and $D_{\text {int }}$ did not suggest any contribution of internal waves or tides to bottom stresses during the deployments (data not shown). 


\section{Discussion}

\subsection{Artifactual Considerations}

The design of the probe assembly makes it potentially subject to artifacts associated with the interaction of boundary layer flows with the exposed probe shaft. Flow of seawater around bluff objects at a variety of scales on the seafloor can induce secondary circulations around the object that can induce pressure gradients at the interface and thus potential Darcian flow within the porespace (e.g., Huettel and Gust 1992; Shinn et al. 2002; De Beer et al. 2005). We cannot exclude the possibility that these effects are active and significant during the 2008 deployments; however, the temperature time series data suggest that any such effects are minor relative to other forcing. Pressure-induced artifacts would be expected to be proportional to shear stresses at the interface. Stresses were tidally periodic and symmetrical during the two deployments, but the calculated flushing events were both tidally asymmetric and highly intermittent. The model detected no convection $\left(D_{\text {int }}<0.1\right)$ within the sediment column for $58 \%$ of the deployment period despite continuous tidal forcing.

Another potential artifact is a non-constant depth of burial of the probe itself due to scour around the base of the probe shaft. During the JJ deployment, a change in the relative temperature response of the first sensor pair changed substantively over less than an hour's time on June 29th (Fig. 3), indicating rapid exposure of the 3-cm thermistor to bottom water. This event was clearly marked in the temperature time series by a collapse of the gradients between the upper two thermistors and an absence of any attenuation or lag in the temperature signal after that point. No analogous episode was identified elsewhere in the record. The data from this period were excluded from the analysis on this basis. We suspect that this was a result of the probe being partially uprooted, but its displacement may also have been accompanied by some scour around the shaft. Model simulations of smaller $(1 \mathrm{~cm})$ variation in the burial depth of the thermistor probe showed little effect on the calculated values of $D_{\text {int }}$ (Wilson et al. 2016).

\subsection{Forcing}

Results of this modeling and observational study in continental shelf sediments reveal previously unconsidered aspects to porewater circulation within permeable marine sediments. The three defining characteristics of mixing on the SAB shelf are its intermittency, its intensity, and its apparent temperature dependence. By intermittency, we mean that there were three distinct periods during which deep mixing was observed: during the latter part of the $\mathrm{JJ}$ record, and early and late in the JA record (Fig. 5d). The intervening periods showed almost no convective mixing, although the lag correlations showed that heat transport into the sediment by conduction was continuous and rapid. Even within the periods during which mixing events were common, the actual episodes of enhanced heat transport were usually limited to a small fraction of each tidal cycle. And, finally, despite $\sim$ constant forcing at the interface by waves and tides over the two deployments, mixing events were restricted to portions of the overall record in which bottom waters were cooling and temperatures at the interface fell below those at depth within the sediment during the flooding portion of each tidal cycle.

Statistical analysis and inspection of the data indicate that during periods of active mixing there was a significant association between periods of higher cross-shelf tidal 
velocity (and consequently bottom stress) and periods of greater median $D_{\text {int }}$ values. Median bottom stresses per se were not significantly different between periods in which large values of $D_{\text {int }}$ were encountered (i.e., during the latter portion of the JJ deployment and the beginning and end of the JA deployment) and when they were absent (the beginning of the $\mathrm{JJ}$ deployment and the middle of the JA deployment), but within those periods in which large values of $D_{\text {int }}$ were encountered, they were associated with greater bottom stresses. In general terms, greater bottom stresses were a necessary, but not a sufficient cause of enhanced mixing episodes.

Our results point out some inherent limitations to correlative time series approaches to estimating exchange rates in systems where exchange may be highly variable in timing and intensity. Our lag correlation analysis of the temperature signal did show a strong diurnal and semidiurnal signal from which it was possible to estimate a temperature propagation rate. However, the bulk of that signal consisted only of the conductive transport of heat into and out of the seabed and is not, by itself, reliable evidence for rates or magnitudes of fluid exchange. Lag models integrate over the dominant periodicity of the background signal (e.g., 12.45 or $24 \mathrm{~h}$ ). On the SAB shelf, the lag method did not capture the episodic injections of heat from advective processes that contributed significantly to the overall transport of heat between bottom water and sediments. The periodicity of flushing is a much more complex function of tidal current velocity, shear stress, and density. Successful models of heat or fluid transport must be responsive on the same time scale as the external forcing.

The interaction of tidal currents with seafloor ripples is likely an important driver for porewater advection at this site. Sonar imagery from our field site indicates a ripple field of $\sim 75 \mathrm{~cm}$ wavelength oriented roughly perpendicular to the dominant tidal axis. The amplitude of the ripples was not measured directly but must be no more than a few centimeters at most, because divers did not report visual evidence of sediment ripples during summertime dives. Flows over long-wavelength, low-amplitude ripples can approximately double the rate and depth of heat transport into sediments relative to a conduction-only case (Cardenas and Wilson 2007a). The imagery suggests that the ripples were asymmetric, with a lee face oriented southeastward. The interaction of the tidal boundary layer with asymmetric ripples is likely to be significantly different on the ebb and flood tides and may explain why we observed a stronger semidiurnal than quarterdiurnal periodicity in flushing. These interactions, and their modulation by changes in wave activity, will produce continuous variation in pressure fields at the interface and continuous adjustments in the rate of heat and solute fluxes within the porespace.

We are confident that the variability in mixing is not a result of migration of the largescale bedforms (e.g., Precht and Huettel 2004). Although sonar imagery of the seafloor is unavailable for most of the summer of 2008, it is available for summer of 2007. Those images show that the only changes to benthic topography between June 7, 2007, and September 18, 2007, were a gradual loss of definition of the ripple field formed during the last strong spring storm. At no point during the 2008 summer season between June 12, 2008, and July 29, 2008, did bottom stresses exceed the maxima measured in 2007 when the bedforms remained stable. The visual similarity of the endpoints of the 2007 and 2008 sonar imagery strongly suggests that the seafloor was stable and immobile during both summers (Fig. 2).

Smaller ripples on the seabed could not be readily resolved by the sonar. Small mobile ripples around the thermistor shaft would have the potential to produce temporally variable heat and solute fluxes within the porespace as the environment responds to changing topography and pressure fields at the interface. Tidal stresses alone were usually 
insufficient magnitude to enable erosion. The sum of both wave and tidal stresses allowed bed stresses to exceed critical shear stress thresholds for medium sands for several hours during most tidal cycles ( $u^{*}$ approximately $1.5 \mathrm{~cm} \mathrm{~s}^{-1}$ : Fig. $5 \mathrm{~b}$ ). Biofilms at the interface can significantly increase the thresholds for sediment motion, however. Chlorophyll content of the upper $5 \mathrm{~mm}$ of the sediment amounts to $\sim 20 \mathrm{mg} \mathrm{m}^{-2}$ (Nelson et al. 1999), which may be sufficient to double the critical shear stress to initiate bed motion (le Hir et al. 2007). This threshold was approached in several instances during the late $\mathrm{JJ}$ and late JA mixing clusters, but not at all during the early JA cluster. Continuous measurement of bed height using a downward-looking acoustic backscatter sensor (ABS) on a nearby tripod revealed no instances of small migratory ripples on the seafloor during the two deployments (G. Voulgaris, unpublished data). Small mobile ripples were observed around benthic instrumentation at the site during late August 2008 (Bell et al. 2012). These ripples formed during a neap tidal period in which benthic stresses were barely above the critical threshold. The sediment oxygen chemocline moved vertically by $\sim 2 \mathrm{~cm}$ within the sediment in response to the ripples, suggesting that changes in porewater fluxes accompanied the changes in bedform geometry (Bell et al. 2012). Given the absence of ripples identified in the ABS data, it is possible that their presence adjacent to the instrument frame represents a wake effect of the bottom currents deflecting around the large object on the seafloor. We also examined the thermal data for oscillations based on the results of Precht et al. (2004), who examined the response of porewater solutes to migrating ripples in a flume. They found that moderately high ripple migration rates $\left(10-20 \mathrm{~cm} \mathrm{~h}^{-1}\right)$ caused oscillation between downwelling and upwelling porewater as the interstitial flows adjusted to the variable gradients at the interface. In our study, however, we did not observe significant oscillation in porewater temperature (associated with downwelling vs upwelling circulation) at greater than semitidal frequencies that might be indicative of reversals in heat fluxes resulting from internal responses to a mobile interface.

No aspect of the interaction of boundary layer flows and sediment or probe geometry can explain the observed correspondence between mixing events and large-scale cooling of the water column. All three clusters of mixing events were preceded by large-scale displacements of cool bottom water by warmer water that allowed large amounts of excess heat to enter into the sediments by conduction. The thermistor probe was too short to account for the additional heat stored at depths greater than $12 \mathrm{~cm}$, but the models record this effect clearly. When the warmer water retreated and was replaced by water that was colder than the porewater, the buoyancy of the porewater promoted convective exchange of warmer pore water across the sediment water interface. These results suggest that repeated warming and cooling trends contribute to instability, allowing greater vertical exchange for a given interfacial pressure forcing than under conditions in which the interfacial thermal gradient was more stable. This is consistent with flume experiments (Boano et al. 2009; Jin et al. 2011) and models (Konikow et al. 2013) that show that small destabilizing density gradients have the capacity to significantly increase the rate and depth of exchange in systems where surficial pressure gradients provide the primary impetus to porewater exchange. Our observations suggest that favorable or unfavorable thermal gradients may either assist or hinder the initiation of porewater exchange even if they may not by themselves be sufficient to induce convective circulation. In this environment, pore water exchange is determined both by local boundary layer forcing and a legacy effect of larger scale changes in shelf circulation.

In this study, field conditions induced deep $(3-12+\mathrm{cm})$ convective circulation in a "pulse and pause" mode. It appears that when forcing at the interface reached a threshold, excess heat at depth was transported quickly out of the sediment by convective fluid 
exchange between the porespace and the overlying water. When forcing was no longer above the threshold level, convective exchange abruptly ceased. Reimers et al. (2004) also noted that flushing could be sudden and intermittent at their LEO-15 site, and attributed the irregular forcing to constructive interaction between the local wave and current fields occurring on time scales on the order of minutes. At our field site on the continental shelf, the forcing was also highly intermittent and the pulses of heat transport were short-lived ( $\sim 1-2 \mathrm{~h}$ on a $12.42 \mathrm{~h}$ tidal cycle). The longer intervals between mixing events emphasize the dominant role of tidal currents, as opposed to wave orbitals, in driving flushing events at this deeper site. Nevertheless, simple current-topography interactions alone were insufficient to induce regular flushing. These results, along with those of Reimers et al. (2004), Hebert et al. (2007) and Cardenas and Jiang (2011), suggest that the interaction of multiple independent forcing factors will produce a non-steady-state flushing response within the seabed in most field settings.

Over the entire deployment period, the total contribution of convective mixing to overall heat exchange was $\sim 1.3 \times$ that of conduction, although individual events could be ca. 20-50× purely conductive heat transport. For biogeochemically relevant solutes such as $\mathrm{O}_{2}$, however, with molecular diffusion coefficients two orders of magnitude smaller that of the diffusivity of heat in a porous medium, the importance of convective mixing episodes to total benthic exchange becomes proportionally greater. At a nearby location on the Georgia continental shelf, Jahnke et al. (2005) used an inverse reaction-diffusion model to estimate that effective exchange of porewater solutes was $>200 \times$ molecular diffusion near the interface and declined exponentially with depth. Our results provide similar estimates overall, but unlike their model, reveal considerable temporal variability in the rate of exchange as a function of changing environmental forcing.

The intermittent pore water exchange modeled from temperature data suggests that the physical forcing at $27 \mathrm{~m}$ in the SAB during the summertime is near a minimal threshold for generating porewater flow. This is particularly evident in the absence of consistent correlation between benthic shear stress calculated for the site and the intensity and timing of mixing that has been seen in studies in shallow, wave-dominated systems (Reimers et al. 2004; Precht and Huettel 2004; Hebert et al. 2007; Fram et al. 2014). On an annual basis, the mixing that we estimated during low energy mid-summer conditions on the mid-shelf represents a likely annual minimum. Fall and winter storms reorganize the seabed into a higher amplitude rippled surface (Nelson and Voulgaris 2014) that will increase the overall rates of advective exchange across the interface, due to both the greater differences in pressure head associated with the rougher topography and the larger contribution of wave orbitals to water velocities and shear stresses at the bed. With more intense forcing, mixing in the winter months may become more frequent than observed in the summer. Longerterm bottom water temperature records (D. Savidge, unpublished data) indicate that crossshelf temperature fronts are present during both summer and winter on the SAB shelf. Winter gradients are reversed, with warmer water offshore and colder water inshore of the study site. Inversion of temperature gradients would occur on the ebb tide rather than the flood tide.

\subsection{Biogeochemical Consequences Porewater Exchange on the SAB Continental Shelf}

The patterns of solute mixing seen in this study will have significant implications for geochemical cycling in mid-shelf porewaters. Most prior studies in the field (e.g., Reimers et al. 2004; Precht and Huettel 2004) or the laboratory (Precht and Huettel 2003; Precht 
et al. 2004) have examined porewater exchange for shorter periods under relatively constant forcing conditions. Consistent forcing allows for the establishment of predictable circulation cells within the porespace with relatively constant zonation of biogeochemical processes. The segregation of redox zones within stable flowpaths has been proposed to limit the efficiency of redox-dependent processes such as denitrification, within permeable sediments (Cardenas et al. 2008; Kessler et al. 2012, 2013, 2014). On the SAB mid-shelf, the intermittent transport seen in the temperature signal during the summer when the energy at the interface is relatively low and benthic topography is muted suggests that oxidants and organic matter are introduced into the sediment only sporadically. As a result, the kinetics of diagenesis may more resemble a batch processor than a continuousflow reactor. Any given location will receive a brief pulse of new substrate and oxidants to depth which will be consumed in situ, leading to a local oscillation between oxidized and reduced porewater, analogous to the conditions observed beneath mobile bedforms (Precht et al. 2004). It has been proposed that oscillation between oxidizing and reducing conditions can lead to more rapid and complete diagenesis than under oxidizing conditions alone (Aller 1994; Hulthe et al. 1998; Sun et al. 2002). The alternation of oxic and anoxic conditions within porespace may also greatly increase the sediment volume in which denitrification is possible, thus accelerating the loss of fixed nitrogen from the continental shelf. A rapid response by sedimentary microbiota to continuous small variation in redox zonation within the porespace as a result of continuous fluctuation in external forcing by waves and tides will enhance the coupling of nitrification and denitrification within sediments and contribute to the high rates of denitrification often observed in permeable sediments (e.g., Laursen and Seitzinger 2002; Rao et al. 2007; Gao et al. 2010).

\section{Conclusion}

Our analysis of thermal data from a site typical of the SAB reveals significant advective exchange of porewaters across the sediment-water interface. Advective exchange occurred preferentially on flood tide during overall cooling trends, indicating that a combination of tidal currents and thermal instability promote flushing events. Advective exchange affected thermal profiles to depths of $40 \mathrm{~cm}$ (5 half depths). Heat transport associated with flushing events commonly exceeded conductive heat transport by an order of magnitude, and averaged $1.3 \times$ that of heat conduction over the entire observation period. Because the period of observation coincided with annual minima of both wave energy and bottom roughness, the calculated flushing likely represents a minimum estimate for the site on an annual basis. The intermittent nature of flushing has important implications for sediment biogeochemistry and sediment-water solute exchanges. The SAB shelf is similar to other sandy subtropical shelves, and the processes contributing to enhanced porewater exchange on the SAB shelf are likely to be active in similar environments worldwide.

Acknowledgments WBS thanks Richard Jahnke for his inspiration and support. We thank Travis McKissack, Corey Metcalfe and Jimmy Williams for their assistance with probe fabrication, Michael Richter, Mary Richards and Trent Moore for diving and deployment, and to the captain and crew of the RV Savannah. We thank Anna Boyette for help with the figures. This material is based upon work supported by the National Science Foundation under Grants OCE-0536326 (WBS) and EAR-1316250 (AMW). Any opinions, findings, and conclusions or recommendations expressed in this material are those of the authors and do not necessarily reflect the views of the National Science Foundation. 
Open Access This article is distributed under the terms of the Creative Commons Attribution 4.0 International License (http://creativecommons.org/licenses/by/4.0/), which permits unrestricted use, distribution, and reproduction in any medium, provided you give appropriate credit to the original author(s) and the source, provide a link to the Creative Commons license, and indicate if changes were made.

\section{References}

Aller RC (1994) Bioturbation and remineralization of sedimentary organic matter: effects of redox oscillation. Chem Geol 114:331-344

Anderson MP (1995) Heat as a ground water tracer. Ground Water 43:951-968

Bell RJ, Savidge WB, Toler SK, Byrne RH, Short RT (2012) In situ determination of porewater gases by underwater flow-through membrane inlet mass spectrometry. Limnol Oceanogr Methods 10:117-128

Berg P, Risgaard-Petersen N, Rysgaard S (1998) Interpretation of measured concentration profiles in sediment pore water. Limnol Oceanogr 43:1500-1510

Berg P, Long MH, Huettel M, Rheuban JE, McGlathery KJ, Howarth RW, Foreman KH, Ghiblin AE, Marin R (2013) Eddy correlation measurements of oxygen fluxes in permeable sediments exposed to varying currents and light. Limnol Oceanogr 58:1329-1343

Bhaskar AS, Harvey JW, Henry EJ (2012) Resolving hyporheic and groundwater components of streambed water flux using heat as a tracer. Water Resour Res. doi:10.1029/2011WR011784

Blanton BO, Werner FE, Seim HE, Leuttich RA Jr, Lynch DR, Smith KW, Voulgaris G, Bingham FM, Way F (2004) Barotropic tides in the South Atlantic Bight. J Geophys Res. doi:10.1029/2004JC002455

Boano F, Poggi D, Revelli R, Ridolfi L (2009) Gravity-driven water exchange between streams and hyporheic zones. Geophys Res Lett. doi:10.1029/2009GL040147

Cardenas MB, Jiang H (2011) Wave-driven porewater and solute circulation through rippled elastic sediments under highly transient forcing. Limnol Oceanogr Fluids Environ 1:23-37

Cardenas MB, Wilson JL (2007a) Effects of current-bed form induced fluid flow on the thermal regime of sediments. Water Resour Res. doi:10.1029/2006WR005343

Cardenas MB, Wilson JL (2007b) Dunes, turbulent eddies, and interfacial exchange with permeable sediments. Water Resour Res. doi:10.1029/2006WR005787

Cardenas MB, Cook PLM, Jiang H, Traykovski P (2008) Constraining denitrification in permeable waveinfluenced marine sediment using linked hydrodynamic and biogeochemical modeling. Earth Planet Sci Lett 275:127-137

Chipman L, Huettel M, Laschet M (2012) Effect of benthic-pelagic coupling on dissolved organic carbon concentrations in permeable sediments and water column in the northeastern Gulf of Mexico. Cont Shelf Res. doi:10.1016/j.csr.2012.06.010

Constantz J (2008) Heat as a tracer to determine streambed water exchanges. Water Resour Res. doi:10. 1029/2008WR006996

Cook PLM, Wenzhofer F, Glud RN, Jannsen F, Heuttel M (2007) Benthic solute exchange and carbon mineralization in two shallow subtidal sandy sediments: effects of advective pore-water exchange. Limnol Oceanogr 52:1943-1963

de Beer D, Wenzhofer F, Ferdelman TG, Boehme SE, Heuttel M (2005) Transport and mineralization rates in North Sea sandy intertidal sediments, Sylt-Romo Basin, Wadden Sea. Limnol Oceanogr 50:113-127

Ehrenhauss S, Huettel M (2004) Advective transport and decomposition of chain-forming planktonic diatoms in permeable sediments. J Sea Res 52:179-197

Elliott H, Brooks NH (1997) Transfer of nonsorbing solutes to a streambed with bed forms: theory. Water Resour Res. doi:10.1029/96/WR02784

Fogaren KE, Sansone FJ, De Carlo EH (2013) Porewater temporal variability in a wave-impacted permeable nearshore sediment. Mar Chem 149:74-84

Fram JP, Pawlak GR, Sansone FJ, Glazer BT, Hannides NK (2014) Miniature thermistor chain for determining surficial sediment porewater advection. Limnol Oceanogr Methods 12:155-165

Franke U, Polarecky L, Precht E, Heuttel M (2006) Wave tank study of particulate organic matter degradation in permeable sediments. Limnol Oceanogr 51:1084-1096

Gao H, Schreiber F, Collins G, Jensen MM, Kostka JE, Lavik G, de Beer D, Zhou HY, Kuypers MMM (2010) Aerobic denitrification in permeable Wadden Sea sediments. ISME J 4:417-426

Gihring TM, Humphrys M, Mills HJ, Heuttel M, Kostka JE (2009) Identification of phytodetritus-degrading microbial communities in sublittoral Gulf of Mexico sands. Limnol Oceanogr 54:1073-1083

Gihring TM, Canion A, Riggs A, Huettel M, Kostka JE (2010) Denitrification in shallow, sublittoral Gulf of Mexico permeable sediments. Limnol Oceanogr 55:43-54

Harrison WD, Musgrave D, Reeburgh WS (1983) A wave-induced transport process in marine sediments. J Geophys Res. doi:10.1029/JC088iC12p07617 
Hatch CE, Fisher AT, Revenaugh JS, Constantz J, Ruehl C (2006) Quantifying surface water-groundwater interactions using time series analysis of streambed thermal records: methods development. Water Resour Res. doi:10.1029/2005WR004787

Hebert AB, Sansone FJ, Pawlak GR (2007) Tracer dispersal in sandy sediment porewater under enhanced physical forcing. Cont Shelf Res. doi:10.1016/j.csr.2007.05.016

Heuttel M, Berg P, Kostka JE (2014) Benthic exchange and biogeochemical cycling in permeable sediments. Ann Rev Mar Sci 6:23-51

Huettel M, Gust G (1992) Impact of bioroughness on interfacial solute exchange in permeable sediments. Mar Ecol Prog Ser 89:253-267

Huettel M, Rusch A (2000) Transport and degradation of phytoplankton in permeable sediment. Limnol Oceanogr 45:534-549

Huettel M, Ziebis W, Forster S, Luther GW III (1998) Advective transport affecting metal and nutrient distributions and interfacial fluxes in permeable sediments. Geochim Cosmochim Acta 62:613-631

Hulthe G, Hulth S, Hall POJ (1998) Effect of oxygen on degradation rate of refractory and labile organic matter in continental margin sediments. Geochim Cosmochim Acta 62:1319-1328

Hunter EM, Mills HJ, Kostka JE (2006) Microbial community diversity associated with carbon and nitrogen cycling in permeable shelf sediments. Appl Environ Microbiol 72:5689-5701

Jahnke RA, Richards ME, Nelson JR, Robertson CY, Rao AMF, Jahnke D (2005) Organic matter remineralization and porewater exchange rates in permeable South Atlantic Bight continental shelf sediments. Cont Shelf Res. doi:10.1016/j.csr.2005.04.002

Janssen F, Heuttel M, Witte U (2005) Pore-water advection and solute fluxes in permeable marine sediments (II): benthic respiration at three sandy sites with different permeabilities (German Bight, North Sea). Limnol Oceanogr 50:779-792

Jin G, Tang H, Li L, Barry DA (2011) Hyporheic flow under periodic bed forms influenced by low-density gradients. Geophys Res Lett. doi:10.1029/2011GL049694

Keery J, Binley A, Crook N, Smith WN (2007) Temporal and spatial variability of groundwater-surface water fluxes: development and application of an analytical method using temperature time series. J Hydrol 336:1-16

Kessler AJ, Glud RN, Cardenas MB, Larsen M, Bourke MF, Cook PLM (2012) Quantifying denitrification in rippled permeable sediments through combined flume experiments and modeling. Limnol Oceanogr 57:1217-1232

Kessler AJ, Glud RN, Cardenas MB, Cook PLM (2013) Transport zonation limits coupled nitrificationdenitrification in permeable sediments. Environ Sci Tech 47:13404-13411

Kessler AJ, Bristow LA, Cardenas MB, Glud RN, Thamdrup B, Cook PLM (2014) The isotope effect of denitrification in permeable sediments. Geochim Cosmochim Acta 133:156-167

Kirillin G, Engelhardt C, Golosov S (2009) Transient convection in upper lake sediments produced by internal seiching. Geophys Res Lett. doi:10.1029/2009GL040064

Komar PD, Neudeck RH, Kulm LD (1972) Observations and significance of deepwater oscillatory ripple marks on the Oregon continental shelf. In: Duane D, Pilkey O, Swift D (eds) Shelf sediment transport. Dowden, Hutchinson and Ross, Stroudsburg, pp 601-619

Konikow LF, Akhavan M, Langevin CD, Michael HA, Sawyer AH (2013) Seawater circulation in sediments driven by interactions between seabed topography and fluid density. Water Resour Res. doi:10.1002/ wrcr.20121

Laursen AE, Seitzinger SP (2002) The role of denitrification in nitrogen removal and carbon mineralization in Mid-Atlantic Bight sediments. Cont Shelf Res. doi:10.1016/S0278-4343(02)00008-0

le Hir P, Monbet Y, Orvain F (2007) Sediment erodability in sediment transport modelling: can we account for biota effects? Cont Shelf Res. doi:10.1016/j.csr2005.11.016

Lee TN, Yoder JA, Atkinson LP (1991) Gulf Stream frontal eddy influence on productivity of the southeast U.S. continental shelf. J Geophys Res. doi:10.1029/91JC02450

Marinelli RL, Jahnke RA, Craven DB, Nelson JR, Eckman JE (1998) Sediment nutrient dynamics on the South Atlantic Bight continental shelf. Limnol Oceanogr 43:1305-1320

Meysman FJR, Galaktionov OS, Cook PLM, Jannsen F, Huettel M, Middelburg JJ (2007) Quantifying biologically and physically induced flow and tracer dynamics in permeable sediment. Biogeosci 4:627-646

Mills HJ, Hunter E, Humphrys M, Kerkhof L, McGuinness Heuttel M, Kostka JE (2008) Characterization of nitrifying, denitrifying, and overall bacterial communities in permeable marine sediments of the northeastern Gulf of Mexico. Appl Enviro Microbiol 74:4440-4453

Moore WS, Wilson AM (2005) Advective flow through the upper continental shelf driven by storms, buoyancy, and submarine groundwater discharge. Earth Planet Sci Lett. doi:10.1016/j.eps1.2005.04.043 
Nelson TR, Voulgaris G (2014) Temporal and spatial evolution of wave-induced ripple geometry: regular versus irregular ripples. J Geophys Res Oceans. doi:10.1002/2013JC009020

Nelson JR, Eckman JE, Robertson CY, Marinelli RL, Jahnke RA (1999) Benthic microalgal biomass and irradiance at the sea floor on the continental shelf of the South Atlantic Bight: spatial and temporal variability and storm effects. Cont Shelf Res. doi:10.1016/S0278-4343(98)00092-2

Precht E, Huettel M (2003) Advective pore-water exchange driven by surface gravity waves and its ecological implications. Limnol Oceanogr 48:1674-1684

Precht E, Huettel M (2004) Rapid wave-drive advective pore water exchange in permeable coastal sediment. J Sea Res 5:93-107

Precht E, Franke U, Polarecky L, Huettel M (2004) Oxygen dynamics in permeable sediments with wavedriven pore water exchange. Limnol Oceanogr 49:693-705

Qian Q, Voller VR, Stefan HG (2008) A vertical dispersion model for solute exchange induced by underflow and periodic hyporheic flow in a stream gravel bed. Water Resour Res. doi:10.1029/2007WR006366

Qian Q, Clark JJ, Voller VR, Stefan HG (2009) Depth-dependent dispersion coefficient for modeling of vertical solute exchange in a lake bed under surface waves. J Hydraul Eng. doi:10.1061/(ASCE)07339429(2009)135:3(187)

Rao AMF, McCarthy MJ, Gardner WS, Jahnke RA (2007) Respiration and denitrification in permeable continental shelf deposits on the south Atlantic Bight: rates of carbon and nitrogen cycling from sediment column experiments. Cont Shelf Res. doi:10.1016/j.csr2007.03.001

Rau GC, Anderson MS, McCallum AM, Ackworth RI (2010) Analytical methods that use natural heat as a tracer to quantify surface water-groundwater exchange, evaluated using field temperature records. Hydrogeol J 18:1093-1110

Reimers CE, Stecher HA III, Taghon GL, Fuller CM, Heuttel M, Rusch A, Ryckelynck N, Wild C (2004) In situ measurements of advective solute transport in permeable shelf sands. Cont Shelf Res. doi:10. 1016/j.csr2003.10.005

Riedl RJ, Huang R, Machan R (1972) The subtidal pump: a mechanism of interstitial water exchange by wave action. Mar Biol 13:210-221

Rocha C (2000) Density-driven convection during flooding of warm, permeable intertidal sediments: the ecological importance of the convective turnover pump. J Sea Res 431:1-14

Rusch A, Heuttel M, Wild C, Reimers CE (2006) Benthic oxygen consumption and organic matter turnover in organic-poor, permeable shelf sands. Aquat Geochem 12:1-19

Santos IR, Eyre BD, Huettel M (2012a) The driving forces of porewater and groundwater flow in permeable coastal sediments: a review. Estuar Coast Shelf Sci 98:1-15

Santos IR, Cook PLM, Rogers L, de Weys J, Eyre BD (2012b) The "salt wedge pump": convection-driven pore-water exchange as a source of dissolved organic carbon and nitrogen to an estuary. Limnol Oceanogr 57:1415-1426

Schmidt C, Büttner O, Musolff A, Fleckenstein JH (2014) A method for automated, daily, temperaturebased vertical streambed water-fluxes. Fundam Appl Limnol/Arch für Hydrobiol. doi:10.1127/18639135/2014/0548

Shinn EA, Reich CD, Hickey TD (2002) Seepage meters and Bernoulli's revenge. Estuar 25:126-132

Shum KT (1992) Wave-induced advective transport below a rippled water-sediment interface. J Geophys Res. doi:10.1029/91JC02101

Silliman SE, Ramirez J, McCabe RL (1995) Quantifying downflow through creek sediments using temperature time series: one-dimensional solution incorporating measured surface temperature. J Hydrol 167:99-119

Smith AJ (2004) Mixed convection and density-dependent seawater circulation in coastal aquifers. Water Resour Res. doi:10.1029/2003WR002977

Stallman RW (1965) Steady one dimensional fluid flow in a semi-infinite porous medium with sinusoidal surface temperature. J Geophys Res. doi:10.1029/JZ070i012p02821

Sun M-Y, Aller RC, Lee C, Wakeham SG (2002) Effects of oxygen and redox oscillation on degradation of cell-associated lipids in surficial marine sediments. Geochim Cosmochim Acta 66:2003-2012

Suzuki S (1960) Percolation measurements based on heat flow through soil with special reference to paddy fields. J Geophys Res. doi:10.1029/JZ065i009p02883

Vance-Harris C, Ingall E (2005) Denitrification pathways and rates in the sandy sediments of the Georgia continental shelf, USA. Geochem Trans 6:12-18

Vogt T, Schneider P, Hahn-Woernle L, Cirpka OA (2010) Estimation of seepage rates in a losing stream by means of fiber-optic high-resolution vertical temperature profiling. J Hydrol 380:154-164

Webb JE, Theodor JL (1972) Wave-induced circulation in submerged sands. J Mar Biol Assoc UK 52:903-914 
Webster IT (2003) Wave enhancement of diffusivities within surficial sediments. Environ Fluid Mech 3:269-288

Webster IT, Norquay SJ, Ross FC, Wooding RA (1996) Solute exchange by convection within estuarine sediments. Estuar Coast Shelf Sci 42:171-183

Wilson AM, Woodward GL, Savidge WB (2016) Using heat as a tracer to estimate the depth of rapid porewater advection below the sediment-water interface. J Hydrol 538:743-753 